MATEC Web of Conferences 3, 01008 (2013)

DOI: $10.1051 /$ matecconf $/ 20130301008$

(C) Owned by the authors, published by EDP Sciences, 2013

\title{
Thermodynamic assessments of the Fe-Y and Ni-Sc systems
}

\author{
S. Kardellass ${ }^{1}$, C. Servant ${ }^{2}$, N. Selhaoui ${ }^{1}$, A. Iddaoudi ${ }^{1}$, M. Ait Amari ${ }^{1}$, and L. Bouirden ${ }^{1}$ \\ ${ }^{1}$ Laboratory of Thermodynamics and Energy (L.T.E), Faculty of Science, B.P 8106, University Ibn Zohr, Agadir, \\ Morocco \\ ${ }^{2}$ Laboratoire de Physicochimie de l'Etat Solide, ICMMO, Université de Paris-Sud, 91405 Orsay Cedex France
}

\begin{abstract}
The present study concerns the optimization of the Fe-Y and Ni-Sc systems by the help of the CALPHAD (CALculation of Phase Diagram) method, taking into account the available experimental results about phase equilibria and thermodynamic properties. The excess terms of the Gibbs energy of the solution phases (liquid, b.c.c., f.c.c. and h.c.p.) were assessed with the recent exponential temperature dependence of the interaction energies by Kaptay and compared with the linear dependence by Redlich-Kister. Furthermore, the computer program Thermo-Calc allows to obtain estimated data for experimentally undetermined thermodynamic properties and to compare the computed phase diagrams with those already published.
\end{abstract}

\section{Introduction}

The intermetallic compounds formed by rare earth elements (RE) and transition metals are of particular interest regarding their potential usage as high-value functional materials, such as permanent magnet and hydrogen storage materials $[1,2]$. To understand the physical compounds, it is necessary to obtain a better knowledge of the thermodynamic properties of this technically relevant system. For example, the thermodynamic assessment of ternary systems such as Ti-Ni-Sc of metallurgical interest needs the thermodynamic evaluation of the low-orders systems such as that of Ni-Sc assessed in the present work.

\section{Experimental}

\subsection{Fe-Y system}

The Fe-Y system has been studied quite thoroughly by various investigators. The first was summarized and assessed critically by Gschneider [3] and later on by Kubuschewski [4]. Both reviews agree in acceptance of the basic diagram proposed by Domagala et al. [5]. However, Gschneider [3] thought that the experimental technique employed by Domagala et al. [5] did not justify drawing the liquidus as a solid line, and Kubuschewski [4] made minor revisions to phase stoichiometries to bring the diagram into accord with the results from more recent crystallographic studies. The latest assessment was carried out by Zhang et al [6]. In this one [6], four intermediate compounds $\mathrm{Fe}_{17} \mathrm{Y}_{2}, \quad \mathrm{Fe}_{23} \mathrm{Y}_{6}, \quad \mathrm{Fe}_{3} \mathrm{Y}$ and $\mathrm{Fe}_{2} \mathrm{Y}$ were detected. According to [7] neither Gschneidner nor
Kubaschewski accepted the existence of an equilibrium phase at a stoichiometry of $\mathrm{YFe}_{5}$, that was reported by Farkas and Bauer [8] and by Nassau et al. [9]. The reasons for rejection of that phase appear justified, and Taylor and Poldy [10] have been unable to find the phase. Further, Subramanian and Smith [11] noted that the alloying behavior of yttrium is generally parallel to that of the heavier lanthanons, and the binary systems $\mathrm{Gd}-\mathrm{Fe}$ [12], TbFe [13], Dy-Fe [14], Ho-Fe [15-17], Er-Fe [18, 19], Bn-Fe [20], and Lu-Fe [20]. Each has the same intermediate phases as in Fig.1 without existence of any $\mathrm{LnFe}_{5}$. A crystallographic study carried out by Zarechnyuk and Kripyakevich [21] found the most iron-rich phase in the $\mathrm{Fe}-\mathrm{Y}$ system to have an ideal stoichiometry of $\mathrm{Fe}_{17} \mathrm{Y}_{2}$ with a $\mathrm{Ni}_{17} \mathrm{Th}_{2}$-type structure. A subsequent study by Buschow [22] found the phase to be dimorphic with the higher temperature form being $\mathrm{Ni}_{17} \mathrm{Th}_{2}$ - $\mathrm{HT}$ type and the lower temperature form being the $\mathrm{Ni}_{17} \mathrm{Th}_{2}$-LT type, but no transition temperature has been established. Kripyakevich et al. [23] and Kharchenko et al. [24] have independently reported the $\mathrm{Fe}_{4} \mathrm{Y}$ phase to have an ideal stoichiometry of $\mathrm{Fe}_{23} \mathrm{Y}_{6}$ and to be isomorphous with $\mathrm{Mn}_{23} \mathrm{Th}_{6}$. Both van Vucht [25] and Buschow [26] have confirmed the existence of a phase with the $\mathrm{Fe}_{3} \mathrm{Y}$ stoichiometry and with the $\mathrm{Ni}_{3} \mathrm{Pu}$-type structure. The most yttrium-rich phase is $\mathrm{Fe}_{2} \mathrm{Y}$, and is a Laves phase with the $\mathrm{Cu}_{2} \mathrm{Mg}$-type structure [27-29]. Van Mal et al. [30] have estimated the heats of formation for the four intermediate phases on the basis of Miedema's theory [31], and Watson and Bennett [32, 33] have developed a simple electron band theory model for predicting the order of magnitude of the heats of formation of alloys between metals with $\mathrm{d}$ and/or $\mathrm{f}$ bands. In addition Ryss et al. [34] measured the integral enthalpies of mixing of liquid Fe-Y alloys by high temperature calorimetry at $1870 \mathrm{~K}$. 


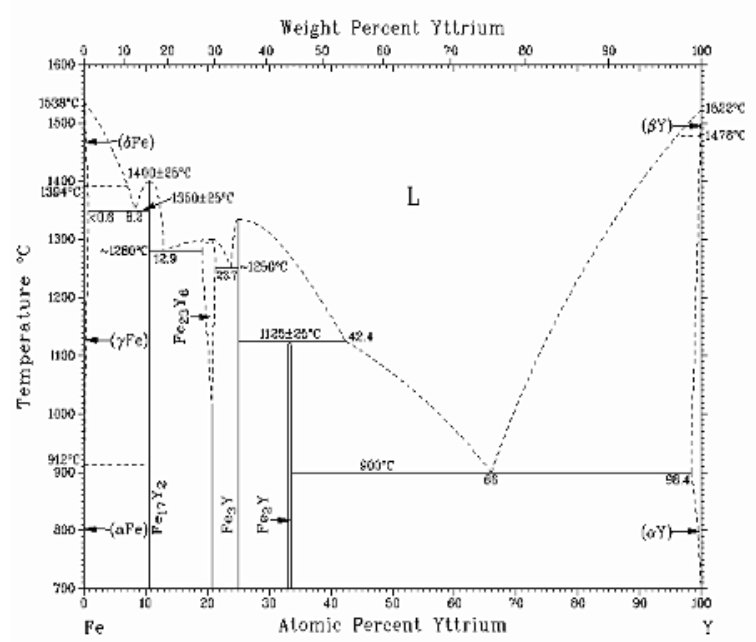

Figure 1. The Fe-Y phase diagram evaluated by [3].

\subsection{Ni-Sc system}

The early investigations on the $\mathrm{Ni}-\mathrm{Sc}$ system were carried out by Markiv et al. [35] using differential thermal analysis (DTA) and X-ray diffractography (XRD) and by Maslenkov et al. [36] using a combination of DTA, microprobe analysis, metallography and (XRD). From the results reported, Nash et al. [37] have constructed a phase diagram. Their work [37] confirmed the existence of the five intermediate phases, $\mathrm{Ni}_{5} \mathrm{Sc}, \mathrm{Ni}_{7} \mathrm{Sc}_{2}, \mathrm{Ni}_{2} \mathrm{Sc}, \mathrm{NiSc}$ and $\mathrm{NiSc}_{2}$. Later, Semenova et al. [38] revised the Ni-Sc phase diagram of $[36,37]$ based on their differential thermal analysis data. A more recent diagram evaluated by Okamoto et al. [39] is shown in Fig. 1 which is based on [38], with the following modification:

- The melting point of $\mathrm{Ni}$, shown at $1655^{\circ} \mathrm{C}$ in [37], is moved to $1455^{\circ} \mathrm{C}$,

- The composition of $\beta \mathrm{Sc}$ in the $\beta \mathrm{Sc} \leftrightarrow \mathrm{L}+\alpha \mathrm{Sc}$ catatectic reaction is shown closer to $100 \% \mathrm{Sc}$ than in [37] originally it was shown at $\sim 90$ at. $\% \mathrm{Sc}$, for consistency with the enthalpy of fusion of $\beta \mathrm{Sc}$,

- The $\mathrm{L} \leftrightarrow \mathrm{NiSc}_{2}+\alpha \mathrm{Sc}$ eutectic composition is labeled to be $\sim 83$ at. $\% \mathrm{Sc}$ in [37], although it is shown < at 80 at. $\%$ Sc.

- NiSc and $\mathrm{NiSc}_{2}$ in [37] are off-stoichiometry higher than 4 and $\sim 6$ at.\% Sc, respectively, but the positions of these compounds have not been modified in Fig.2.

- An invariant reaction at $\sim 830^{\circ} \mathrm{C}$ between $\mathrm{NiSc}$ and $\mathrm{NiSc}_{2}$ is not related to a melting reaction and may be caused by impurities of Sc [37].

The solubility of scandium in nickel has also been investigated by $[35,36]$. Partial phase diagrams of the system have been proposed in the composition ranges lower than 80 at \% Sc [35] and 40 at. \% Sc [36].

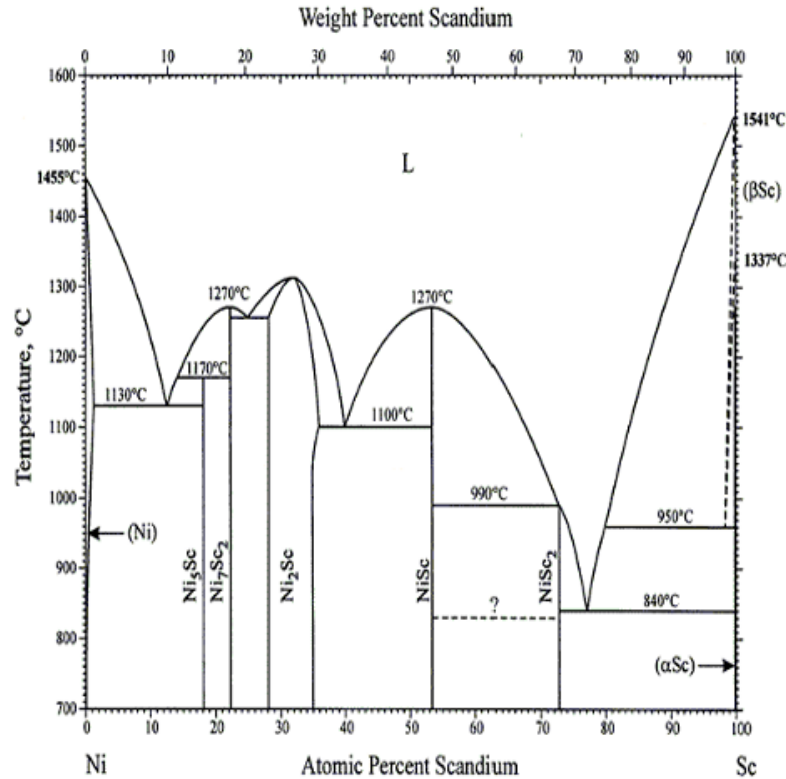

Figure 2. The Ni-Sc phase diagram evaluated by [34].

Braslavskaya et al. [40] have found a phase transition of $\mathrm{Ni}_{5} \mathrm{Sc}$ at $1153 \pm 20 \mathrm{~K}$. However, the structure of the lowtemperature modification is not known. The structures of $\mathrm{Ni}_{5} \mathrm{Sc}_{-} \mathrm{HT}, \mathrm{Ni}_{7} \mathrm{Sc}_{2}, \mathrm{NiSc}$, and $\mathrm{NiSc}_{2}$ have been respectively determined by [36, 41-43].

The enthalpies of mixing of the liquid phase up to 20 at. $\%$ Sc have been determined by high temperature calorimetry by [44] and the enthalpies of formation of the compounds have been measured by [45]. The predicted ones are listed in [46]. Furthermore, the Gibbs'energy change during the formation of the different compounds from the solid components have been determined at $\mathrm{T}=988$ $\mathrm{K}$ by [47].

\section{Modeling}

\subsection{Unary phases}

The Gibbs energy function $G_{i}^{\phi}(T)={ }^{0} G_{i}^{\phi}-H_{i}^{S E R}$ $(298.15 \mathrm{~K})$ for the element $\mathrm{i}(\mathrm{i}=\mathrm{Fe}, \mathrm{Y}$ or $\mathrm{Ni}, \mathrm{Sc})$ in the $\Phi$ phase ( $\Phi=$ Liquid, BCC, FCC and HCP is described by an equation of the following form:

$G_{i}^{\phi}(T)=a+b T+c T \ln T+d T^{2}+e T^{3}+f T^{-1}$

$+g T^{7}+h T^{-9}$

where: ${ }^{\lambda} L_{i, j}^{\phi}(298.15 \mathrm{~K})$ is the molar enthalpy of the element $i$ at $298.15 \mathrm{~K}$ in its standard element reference (SER) state, BCC for Fe, HCP for Y, FCC for Ni and HCP for Sc. In this paper, the Gibbs energy functions are taken from the SGTE compilation of Dinsdale [48].

\subsection{Liquid phase}

The liquid phase was assessed with the recent exponential temperature dependence of the interaction energies by Kaptay [49-51] and compared with the linear model by Redlich-Kister [52]. 
The Gibbs energy of one mole of formula unit of phase is expressed as the sum of the reference part ${ }^{r e f} G$, the ideal part ${ }^{i d} G$, the excess part ${ }^{x s} G$ and the magnetic part $\operatorname{mag}_{G_{m}^{\phi}}$.

$G_{m}^{\phi}(T)={ }^{r e f} G_{m}^{\phi}{ }^{i d} G_{m}^{\phi}{ }^{\phi s} G_{m}^{\phi}{ }^{m a g} G_{m}^{\phi}$

The excess terms of all the phases were modelled by the Redlich-Kister model [51].

${ }^{x s} G_{m}^{\phi}(T)=x_{i} x_{j} \sum_{\lambda=0}^{\lambda} L_{i, j}^{\phi}(T)\left(x_{i}-x_{j}\right)^{\lambda}$

where ${ }^{\lambda} L_{i, j}^{\phi}$ is the $\lambda$ th interaction parameter between the elements $\mathrm{Fe}$ and $\mathrm{Y}$ or $\mathrm{Ni}$ and $\mathrm{Sc}$ which is evaluated in the presented work according to:

** the linear model of Redlich-Kister of temperature dependence

$\lambda_{L} L_{i, j}^{\phi}(T)=a_{\lambda}+b_{\lambda} T$

$a_{\mathrm{i}}$ and $b_{\mathrm{i}}$ are the coefficients to be optimized,

** the Kaptay model of exponential temperature dependence

$\lambda L_{i, j}^{\phi}=h^{\lambda} * \exp \left(-\frac{T^{*} s^{\lambda}}{h^{\lambda}}\right)$

$h^{\lambda}$ enthalpy part and $s^{\lambda}$ entropy part to be optimized.

The ${ }^{0} G_{M E}$ and ${ }^{0} G_{R E}$ are the Gibbs energies of the pure elements $\mathrm{ME}(\mathrm{Fe}, \mathrm{Ni})$ and $\mathrm{RE}(\mathrm{Y}, \mathrm{Sc})$.

$\mathrm{Fe}_{17} \mathrm{Y}_{2}$ and $\mathrm{Fe}_{3} \mathrm{Y}$ have been treated as stoichiometric compounds while $\mathrm{Fe}_{23} \mathrm{Y}_{6}$ (extension of one part to the other around 0.206 at. $\mathrm{Y}$ ) and $\mathrm{Fe}_{2} \mathrm{Y}$ (substoichiometric in $\mathrm{Y}$ ) which have a homogeneity range were treated as the formula $(\mathrm{Fe}, \mathrm{Y})_{0.794}(\mathrm{Fe}, \mathrm{Y})_{0.206}$ and $(\mathrm{Fe})_{0.667}(\mathrm{Fe}, \mathrm{Y})_{0.333}$ by a two sublattice model of $\mathrm{Fe}$ and $\mathrm{Y}$. A solution model has been used for the description of the liquid phase and the $(\alpha \mathrm{Fe}),(\gamma \mathrm{Fe}),(\alpha \mathrm{Y})$ and $(\beta \mathrm{Y})$ solid solutions.

The Miedema theory [31] predicts enthalpies of Fe$\mathrm{Y}$ phase formation of about $-2 \mathrm{~kJ} / \mathrm{gm}$-atom. In contrast, the Watson-Bennett model [32] predicts enthalpies of phase formation to be about $-13 \mathrm{~kJ} / \mathrm{gm}$-atom An interpolated value by Subramanian et al [11] of -5.3 $\mathrm{kJ} / \mathrm{gm}$-atom for an equiatomic alloy at $973 \mathrm{~K}$ was obtained.

In order to avoid the formation of an artificial inverted miscibility gap above the liquidus line as suggested by $[53,54]$ in the case of the linear model, the stability constraint was enforced by requiring that the Gibbs energy of the liquid phase had a positive curvature $\left(\partial^{2} G / \partial x^{2}>0\right)$ at all compositions and temperatures up to $4000 \mathrm{~K}$.

\subsection{Stoichiometric compounds}

The Gibbs energy of the stoichiometric compounds ${ }^{0} G_{m}^{M E m R E n}$ is expressed as follows where the parameters $a$ and $b$ to be determined

${ }^{0} G_{m}^{M E m R E n}=\frac{m}{m+n}{ }^{0} G_{M E}+\frac{n}{m+n}{ }^{0} G_{R E}+a+b T$
In the $\mathrm{Ni}-\mathrm{Sc}$ system, the four intermediate phases $\mathrm{Ni}_{5} \mathrm{Sc}$, $\mathrm{Ni}_{5} \mathrm{Sc}_{2}, \mathrm{Ni}_{2} \mathrm{Sc}$ and $\mathrm{NiSc}$ were modeled as stoichiometric and $\mathrm{Ni}_{2} \mathrm{Sc}$ with a composition range as $(\mathrm{Ni}, \mathrm{Sc})_{0.667}(\mathrm{Ni}, \mathrm{Sc})_{0.333}$.

The optimisation procedure was carried out with the Calphad method [55] using the Parrot module [56] in two steps. First stoichiometric compounds then composition range were used.

\section{Results and discussion}

The calculated Fe-Y phase diagram shown in Fig. 3 was optimized with the Redlich-Kister linear model [52]. A zoom is in Fig. 4.

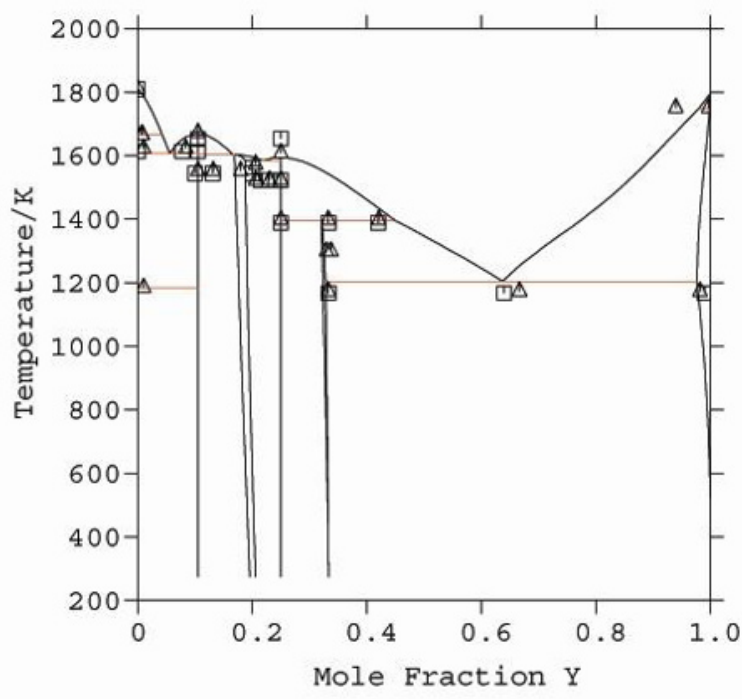

Figure 3. Calculated $\mathrm{Fe}-\mathrm{Y}$ phase diagram using the thermodynamic parameters optimized with the Redlich-Kister linear model of temperature dependence (continuous line) and the experimental data $\square[3], \Delta[6]$.

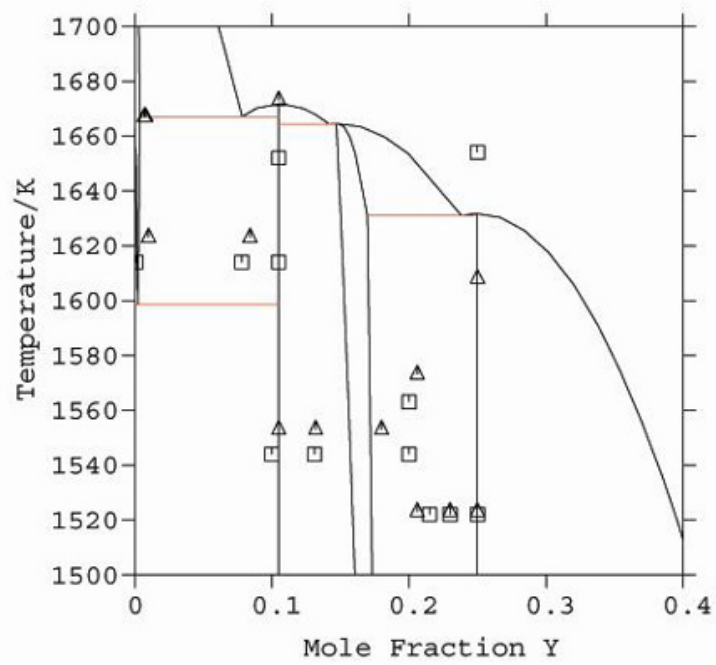

Figure 4. Zoom of the above calculated Fe-Y phase in the Fe rich corner and at high temperatures, $\square[3], \Delta[6]$.

The phase diagram calculated with the exponential temperature dependence of the Kaptay model [49-51] is shown in Fig. 5. It will be noted that the calculated (Figs. 3-4-5) and the experimental (Fig. 1) phase diagrams are in 
reasonable agreement, except on the one hand for the congruent melting of the $\mathrm{Fe}_{23} \mathrm{Y}_{7}$ compound which is calculated too high with the two models, but this part of the experimental diagram is not very sure (dotted lines on Fig. 1), and on the other hand for the liquidus curvature in the $\mathrm{Y}$ rich part. The calculated integral enthalpy of mixing of the liquid phase at $\mathrm{T}=1870 \mathrm{~K}$ is compared with the experimental one [11] in Fig. 6. The agreement is satisfactory.

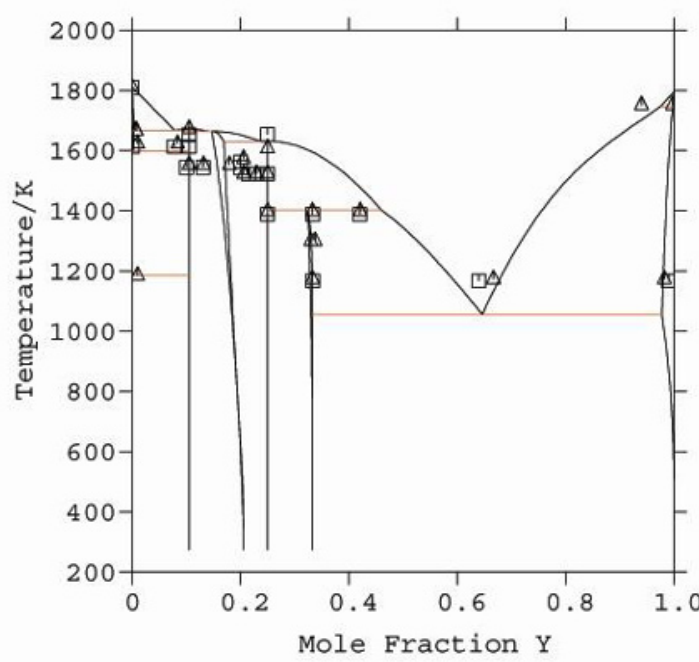

Figure 5. Calculated $\mathrm{Fe}-\mathrm{Y}$ phase diagram using the thermodynamic parameters optimized with the Kaptay model and experimental data $\square[3], \Delta[6]$.

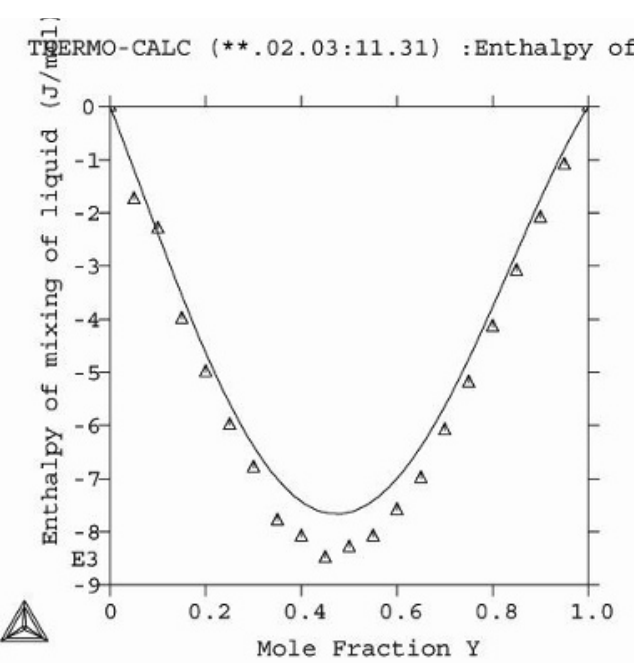

Figure 6. Comparison of the calculated integral enthalpy of mixing of the liquid of the Fe-Y system at $1870 \mathrm{~K}$ using the thermodynamic parameters optimized with the Kaptay model (continuous line) and the experimental ones $\Delta[11]$.

The predicted, calculated and experimental ( $\mathrm{T}=973 \mathrm{~K})$ enthalpies of formation of the compounds are shown in Fig. 7. The discrepancy is higher for the $\mathrm{FeY}_{2}$ compound.

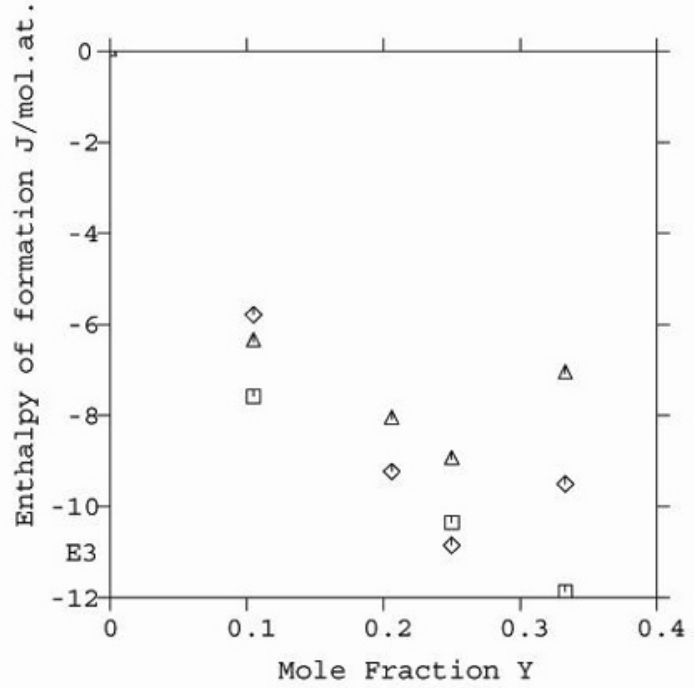

Figure 7. Comparison of the calculated enthalpies of formation of the Fe-Y compounds at $\mathrm{T}=973 \mathrm{~K}$ (this work with: $\square$ the Kaptay model, $\downarrow$ the Redlich-Kister model) with the experimental ones $\Delta$ [6].

The Ni-Sc calculated phase diagram with the Kaptay model is compared with the experimental data of [38] in Fig. 8. A very good agreement is observed except for the liquidus part in the $0.7-0.8$ at. Sc range.

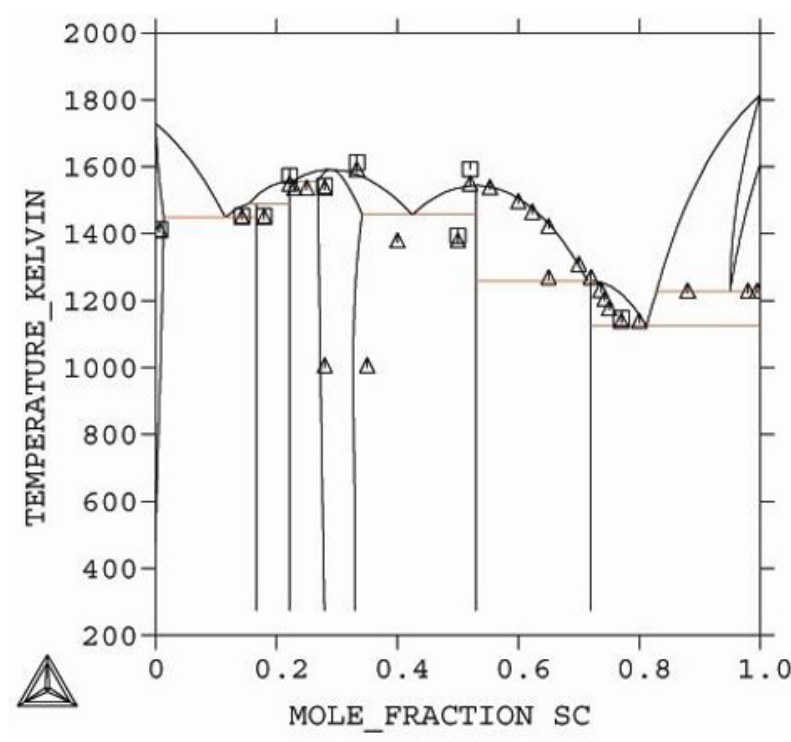

Figure 8. Calculated Ni-Sc phase diagram (continuous line) using the thermodynamic parameters optimized with the Kaptay model and the experimental data: $\square[38], \Delta[35]$.

The calculated integral enthalpies of mixing of the liquid phase at $\mathrm{T}=1750 \mathrm{~K}$ are compared in Figure 9. A very good agreement is noted. 


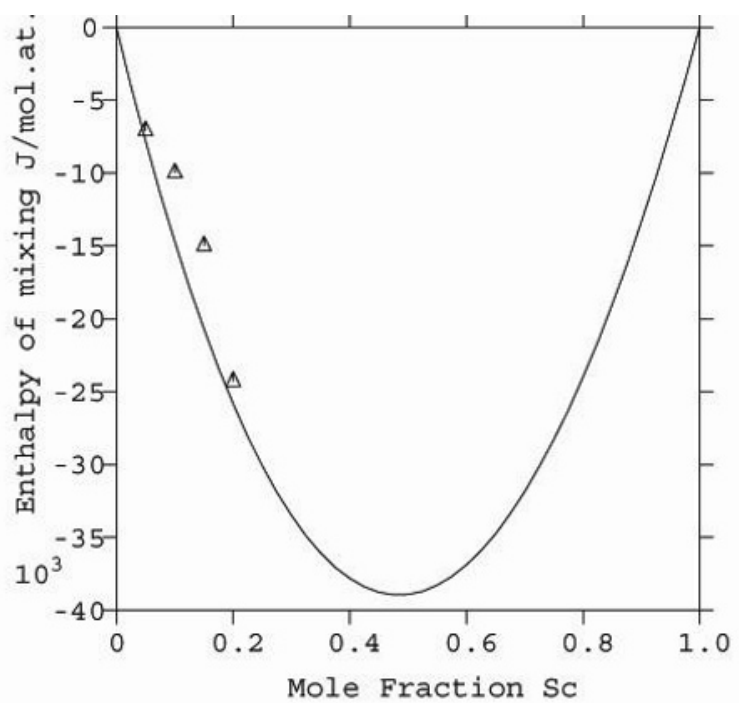

Figure 9. Comparison of the calculated integral enthalpy of mixing of the Ni-Sc system ( $\mathrm{T}=1750 \mathrm{~K})$, using the thermodynamic parameters optimized with the Kaptay model, and with the experimental data $\Delta$ [44].

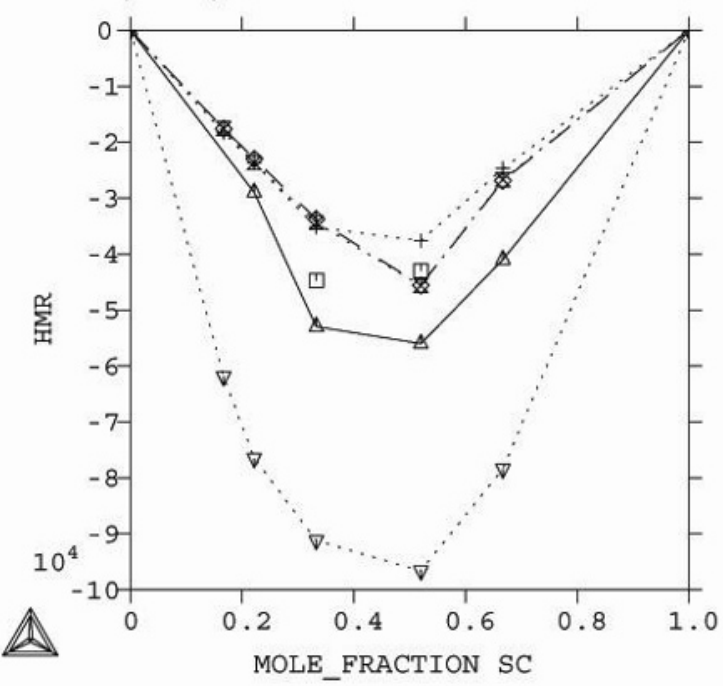

Figure 10. Comparison of the experimental $\square$ [45], predicted $\Delta[46]$ and optimized enthalpies of formation of the compounds [this work with, + the Kaptay model, $\downarrow$ the Redlich-Kister model]. $\boldsymbol{\nabla}$ Gibbs'energy of formation at 988 K by [47].

The calculated enthalpy of formation of the compounds (noted: + (Kaptay model) or $\downarrow$ Redlich-Kister model), shown in Fig. 10 is compared with the experimental ones $\square$ at $\mathrm{T}=988 \mathrm{~K}[45], \circ[38]$ and predicted $\Delta[46]$. A reasonable agreement is noted. The Gibbs'energy change during the intermetallic formation at $988 \mathrm{~K}$ was determined by [47].

\section{Conclusion}

A convenient set of thermodynamic parameters have been optimized for the two Fe-Y and Ni-Sc systems. The linear or exponential temperature dependence of the excess parameters of the solution phases led to the equivalent calculated phase diagrams. In both cases, further experimental determination of the enthalpies of mixing of the liquid phase and of the enthalpies of formation of the compounds will be welcome to improve the thermodynamic assessments.

\section{References}

1. K.H.J. Buschow, Rep. Prog. Phys. 401179 (1977)

2. K.H.J. Buschow, Mater. Res. Bull. 19935 (1984)

3. K.A. Gschneider Jr., Binary Alloy Systems Rare Earth Alloys, D. Van Nostrand Co., New York, (1961)

4. O. Kubaschewski,, Iron-Binary Phase Diagrams, Springer-Verlag, New York, (1982)

5. R.E. Domagala, J.J. Rausch, D.W. Levinson, Trans. ASM 53139 (1961)

6. W. Zhang, G. Liu, K. Han, J. Phase Equilibria 13304 (1988)

7. R.P. Elliot, Constitution of binary alloys First Supplement, New York: McGraw-Hill, (1965)

8. M.S. Farkas and A.A. Bauer, U.S. AEC Report BMI138620 (1959)

9. K. Nassau, L.V. Cherry, W.E. Wallace, J. Phys. Chem. Solids 16123 (1960)

10. K.N.R. Taylor and C.A. Poldy, J. Less-Common Metals 7255 (1972)

11. P.R. Subramanian, J.F. Smith, Calphad 8295 (1984)

12. E.M. Savitskii, V.F. Terekhova, R.S. Torchinova, I.A. Markova, O.P. Naumkin, V.W. Koleshnichenko, V.F. Stroganova, Les Eléments Des Terres Rares 1, Centre National De La Recherche Scientifique, Paris, 1970

13. M.P. Dariel, J.T. Holthuis, M.R. Pickus, J. LessCommon Metals 4591 (1976)

14. A.S. van der Goot and K.H.J. Buschow, J. LessCommon Metals 2l 15 (1970)

15. T.J. O'Keefe, G.J. Roe, W.J. James, Proc. 6th Rare Earth Research Conf. (May 3-5, 1967) Gatlinburg, Tennessee

16. T.J. O'Keefe, G.J. Roe, W.J. James J. Less-Common Metals 15357 (1968)

17. G.J. Roe and T.J. O'Keefe, Met. Trans. 12565 (1970)

18. K.H.J. Buschow and A.S. van der Goot, Phys. Stat. Sol. 2515 (1969)

19. A. Meyer, J. Less-Common Metals 4141 (1969)

20. V.E. Kolesnichenko, V.F. Terekova, E.M. Savitskii, Metallovedenie Tsvetnykh Metallov I Splavov, ed. by M. E. Drits, Izdatelistvo Nauka, Moscow (1972)

21. O.S. Zarechnyuk and P.I. Kripyakevich: Dopov, Akad. Nauk Ukr. RSR 121593 (1964)

22. K.H.J. Buschow, J. Less-Common Metals 11204 (1966)

23. P.I. Kripyakevich, D.P. Frankevich, Y.V. Voroshilov, Porosh, Met. 1155 (1965)

24. O.I. Kharchenko, O.I. Bodak, E.I. Gladyshevskii, Russ. Metall. 1170 (1976)

25. J.H.N. van Vucht, J. Less-Common Met. 10147 (1965)

26. K.H.J. Buschow: Philips Res. Rep. 2649 (1971)

27. B.J. Beaudry, J. Haefling, A.H. Daane, Acta Cryst. IJ $743(1960)$

28. A.E. Dwight, Trans. Am. Sot. Met. 2479 (1961)

29. K. Nassau, L.V. Cherry, W.E. Wallace, J. Phys. Chem. Solids 16123 (1960) 
30.E.I. Krypyakevich, D.E Frankevich, Y.V. Voroshilov, Poroshlc MetaUo 1155 (1965)

31. A.R. Miedema, J. Less-Common Metals 4667 (1976)

32. L.H. Bennett and R.E. Watson, Calphad 523 (1981)

33. R. E. Watson L. H. Bennett, Calphad 140 (1981)

34. G.M. Ryss, A.I. Stroganov, Y.O. Esin, EV. Geld, Zh. Fiz. Khim. 50(3) 771

35. V.Ya. Markiv, I.S. Gavrilenko, V.V. Pet'kov, N.N. Belyavina, Metalofizika 7339 (1978)

36. S.B. Maslenkov, G.S. Braslavskaya, lzv. Akad. Nauk. SSSR. Met. 1203 (1984)

37. P. Nash and Y.Y. Pan, Phase diagrams of binary Nickel Alloys, P. Nash, ed., ASM International, Materials Park, OH, (1991)

38. E.L. Semenova, N.Y. Rusetskya, J. Alloy Compounds, 262-263 258 (1997)

39. H. Okamoto, J. Phase Equilibria 21110 (2000)

40. G.S. Braslavskaya, S.B. Malenkov, lzv. Akad. Nauk. SSSR Met. 1107 (1987)

41. J.A. Goebel, S. Rosen, J. Less-Common Met. 16 441 (1968)

42. A.E. Dwight, Trans. Am. Soc. Met. 53479 (1961)

43. A.T. Aldred, Trans. Metal. Soc. AIME 2241082 (1962)

44. Yu.O. Esin, S.E. Demin, V.V. Litovskii, J. Phys. Chem. 59131 (1985)

45. N. Selhaoui, OJ. Kleppa, J Alloys Comp. 191145 (1993)

46. F.R. De Boer, R. Boom and A. R. Miedema, Physica, 101B 294 (1980)

47. A.I. Kononvo and E.G. Polyakov, J. Alloy Comp. 239107 (1996)

48. A.T. Dinsdale, Calphad 15317 (1991)

49. G. Kaptay, Calphad 28-2 115 (2004)

50. G. Kaptay, Calphad 32-2 338 (2008)

51. G. Kaptay, Mat. Sci. Eng. A 49519 (2008)

52. O. Redlich, A. Kister, Ind. Eng. Chem. 40345 (1948)

53. C.H. Lupis, Chemical Thermodynamic of Metals, Prentice-Hall Inc., North-Holland, NY, (1983)

54. K.C. Kumar, P. Wollants, J Alloys Comp. 320-2 189 (2011)

55. L. Kaufman, H. Bernstein, Computer Calculations of Phase Diagrams, Academic Press, New-York, NY (1970)

56. B. Sundman, B. Jansson, J.-O. Andersson, Calphad, 2153 (1985) 